\title{
Gender-Wise Comparative Assessment of Lifestyle Patterns and Well-Being Status among Healthcare Employees at a Tertiary Care Hospital
} \author{
Mounica Reddy Pillaram ${ }^{1}$ \\ ${ }^{1}$ Department of Cardiology, Sri Venkateswara Institute of Medical \\ Sciences, Tirupati, Andhra Pradesh, India \\ ${ }^{2}$ Department of SPM, Narayana Medical College, Nellore, Andhra \\ Pradesh, India \\ ${ }^{3}$ Department of Psychiatry, Sri Venkateswara Medical College, \\ Tirupati, Andhra Pradesh, India
}

Vanajakshamma Velam ${ }^{1}$ Vyshnavi Kancherla ${ }^{2} \quad$ Latheef Kasala $^{1} \quad$ Anusha Kancherla $^{3}$

\begin{abstract}
Address for correspondence Dr. V. Vanajakshamma, MD, DM, FCSI, FISC, Professor, Department of Cardiology, Sri Venkateswara Institute of Medical Sciences, Alipiri Road, Tirupati-517507, Andhra Pradesh, India (e-mail: vvanaja1966@yahoo.in).
\end{abstract}

\begin{abstract}
Keywords

- lifestyle

- well-being

- healthcare employees

- gender-wise comparison.

Background This study was an attempt to assess and compare the gender-wise lifestyle patterns and well-being status among the employees of a tertiary care teaching hospital.

Material and Methods This is a cross-sectional, questionnaire-based study conducted at a tertiary care hospital between May and August 2019. A total of 777 employees belonging to both genders (male and female) and working at different professional levels were assessed. All the enrolled employees were subjected to a comprehensive study tool consisting of various dimensions of their health, which included physical, mental, social, spiritual and intellectual health dimensions.

Results Among the participants, 327 (42.1\%) were male and 450 (57.9\%) were female. There was no significant difference in the mean age of male (37.91 \pm 7.52$)$ and female $(36.85 \pm 8.16)$ employees $(p=0.07)$. A significantly higher proportion of diabetes and hypertension were seen in male employees ( $9.8 \%$ and $14.4 \%$, respectively) than in female ( $5.6 \%$ and $6.2 \%$ respectively). The overall well-being was better in male employees than in females and was statistically significant $(p<0.0001)$. We found that male employees had statistically significant better well-being in terms of physical, mental and social health whereas female employees had intellectual health.

Conclusion The overall well-being in healthcare staff was good at our tertiary care hospital, and the outstanding/good well-being rate was higher in male employees than in female employees. Female employees experienced risks with regard to their physical health.
\end{abstract}

published online April 13, 2021
DOI https://doi.org/ $10.1055 / \mathrm{s}-0041-1727578$ (c) 2021. Women in Cardiology and Related Sciences.

This is an open access article published by Thieme under the terms of the Creative Commons Attribution-NonDerivative-NonCommercial-License, permitting copying and reproduction so long as the original work is given appropriate credit. Contents may not be used for commercial purposes, or adapted, remixed, transformed or built upon. (https://creativecommons.org/licenses/by-nc-nd/4.0/).

Thieme Medical and Scientific Publishers Pvt. Ltd. A-12, 2nd Floor, Sector 2, Noida-201301 UP, India 


\section{Abstract Image}

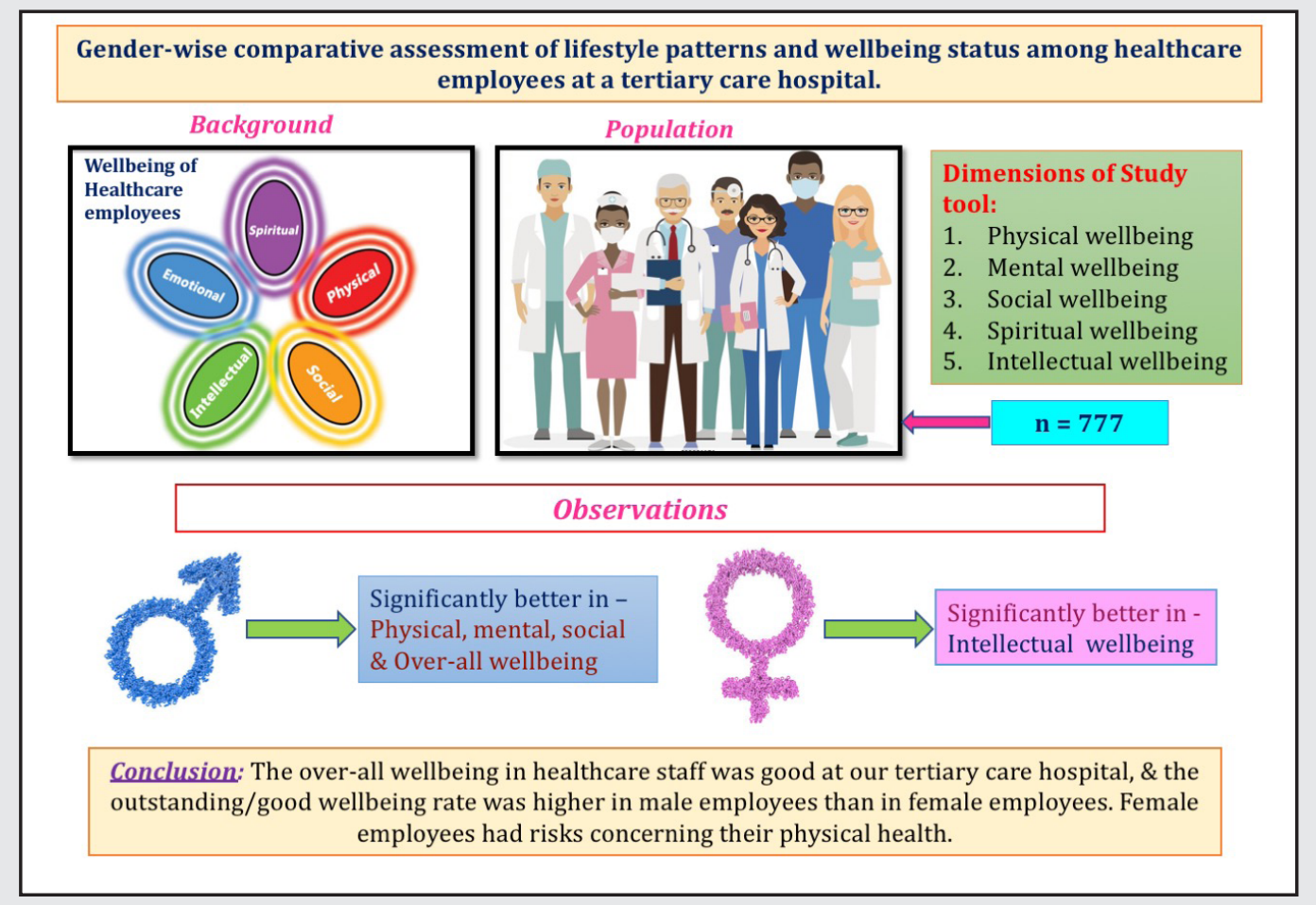

\section{Introduction}

Health is defined as "a state of complete physical, mental and social wellbeing and not merely the absence of disease or infirmity." ${ }^{1}$ Healthy lifestyle possesses many advantages in the prevention of several lifestyle/noncommunicable diseases (NCDs), irrespective of the age, gender, profession and geographical location. A healthy dietary lifestyle and exercise minimizes the risk of cardiovascular diseases, reduce anxiety and depression, lowers the cholesterol levels, and boosts the immune system. ${ }^{2-4}$

The burden of NCDs are rising globally. As an action plan, India, in its National Health Policy 2017, reckoned to reduce the number of premature deaths by $25 \%$ from NCDs by $2025 .{ }^{5}$ In the management of NCDs, lifestyle measures such as promoting physical activity, healthy dietary habits, stress management, avoidance of tobacco products and alcohol intake and, most importantly, increased awareness about the condition are of paramount importance to minimize the risk of NCDs. Controlling obesity, avoiding an unhealthy diet, and promoting physical activity could prevent $80 \%$ of heart diseases, stroke, and diabetes mellitus. ${ }^{6,7}$ Lifestyle modification is inevitable for being healthy at all stages of prevention. ${ }^{8}$

Mental health is another factor affecting the well-being of healthcare professionals. WHO has defined mental health as the ability to have a proper relationship with people, change or improve personal or social environment, and solve the paradoxes of personal tendencies logically and properly. ${ }^{9}$

There are some pieces of evidence proving that regular physical activity reduces the level of anxiety and depression, by improving mental health, and increases the level of satisfaction and quality of life. ${ }^{10-12}$
Lack of proper knowledge on nutrition and physical activity, lack of acceptance to change behavior, and self-motivation are the limitations to change the individual's lifestyle. To the best of our knowledge, limited studies have been published comparing the gender-wise lifestyle patterns and well-being status among healthcare professionals. Hence, an attempt has been made to assess the gender-wise lifestyle patterns and well-being status among the employees of our tertiary care teaching hospital.

\section{Material \& Methods}

The present study is a cross-sectional, questionnaire-based study conducted at our institute from May to August 2019. A total of 777 employees, in which 327 male and 450 female employees working at different professional levels, were enrolled into the study.

Inclusion and Exclusion Criteria: Employees of either sex willing to participate in the study were enrolled. Employees who had refused to give consent or refused to complete the study tool were excluded.

Regulatory approvals: The local Institutional Ethics Committee approved this study with IEC No. 896 (approval dated 23-04-2019). A written informed consent was obtained from all the participants before they participated in the study.

\section{Study Tool ${ }^{13,14}$ :}

The well-being assessment tool used in this study was a validated and standardized one consisting of five well-being components: physical health dimension, mental health dimension, social health dimension, spiritual health dimension, and intellectual health dimension along with general demographic 
details of the participants. Each well-being component had five questions with a maximum score of 25 . The scoring pattern and health status of individual was correlated as follows-

\begin{tabular}{|l|l|}
\hline Well-being score & Status of well-being \\
\hline $23-25$ & Outstanding \\
\hline $19-22$ & Good \\
\hline $13-18$ & Some well-being risks \\
\hline$<12$ & Serious risks with health \\
\hline
\end{tabular}

\section{Data Collection}

All the enrolled employees were subjected to a detailed study tool consisting of various dimensions of health, including physical health dimension, mental health dimension, social health dimension, spiritual health dimension, and intellectual health dimension. The scoring system was awarded for each question from 1 to 5 .

Data Analysis: Observations were captured on paper case record forms initially and transcribed into MS Excel spreadsheets. Data was analyzed using Statistical Package for Social Sciences (SPSS) version 25.0. (IBM Corp, Somers, NY, USA). The results were expressed as mean \pm standard deviation (SD) and frequencies with percentages for continuous and categorical variables, respectively. Differences between male and female groups were tested for statistical significance using Fischer's exact test and Chi-squared tests as appropriate for categorical variables. Independent student's $t$-test was used to test the statistical significance of continuous variables between male and female groups. A $p$ value $\leq 0.05$ was considered as statistically significant.

\section{Results}

The current study enrolled a total of 777 subjects of both genders belonging to various professions working in tandem at a tertiary care teaching hospital. The mean age of the study group was $37.38 \pm 9.74$ years (range: $17-68$ years). Among the participants, 327 (42.1\%) were male and 450 (57.9\%) were female. There was no significant difference in the mean age of males (37.91 \pm 7.52$)$ and female (36.85 \pm 8.16$)$ employees
( $p=0.07$ by independent student's $t$-test). The demographic characteristics of the male and female employees were summarized in - Table 1.

\section{Lifestyle Characteristics}

Most of the study participants were doing moderate physical activity (67.6\%), and we found no significant difference in physical activity between male and female employees ( $p=$ $0.486)$. There was a significant difference in practicing strict exercise between male and female employees (43.4\% vs. $32.4 \% ; p=0.002$ ). The practice of strict exercise was observed less in female employees when compared with male. There was no significant difference in meditation practice, yoga, dietary pattern, and abnormal food intake between both genders. The majority of the male and female employees avoided bad food that is harmful to health and found no significant difference between males and females. Diabetes and hypertension were observed less in female employees than male employees ( $p=0.036$ and $p<0.0001$, respectively). Lifestyle characteristics were summarized in - Table 2.

\section{Assessment of Well-being Characteristics}

The overall well-being was better in male employees than in females and was statistically significant $(p<0.0001)$. We found that male employees had statistically significant better well-being in terms of physical, mental, and social health, whereas female employees had better intellectual health. There is no significant difference in terms of spiritual health. The individual well-being scores related to physical, mental, social, spiritual, and intellectual health were shown in - Table 3.

\section{Discussion}

The results of this study showed that there is a significant difference between male and female employees in terms of exercise practice, diabetes, and hypertension. Although exercise practice is higher in male employees, diabetes and hypertension are also reported higher in male employees. We found a significant difference in physical, mental, social, intellectual health and overall well-being score between male and female employees. However, no significant difference

Table 1 Comparison of demographic details of the study participants

\begin{tabular}{|l|l|l|l|l|}
\hline \multicolumn{2}{|l|}{ Characteristic } & Male $(\boldsymbol{n}=327)$ & Female $(\boldsymbol{n}=450)$ & $p$ value \\
\hline Age (years) & & $37.91 \pm 7.52$ & $36.85 \pm 8.16$ & 0.07 \\
\hline Marital status & Married & $258(78.9 \%)$ & $394(87.6 \%)$ & $0.001^{*}$ \\
& Unmarried & $69(21.1 \%)$ & $56(12.4 \%)$ & \\
\hline \multirow{2}{*}{ Education } & School level & $67(20.5 \%)$ & $84(18.7 \%)$ & 0.123 \\
& Under graduation & $161(49.2 \%)$ & $254(56.4 \%)$ & \\
& Postgraduation & $99(30.3 \%)$ & $112(24.9 \%)$ & $<0.0001^{*}$ \\
& Professional & $35(10.7 \%)$ & $51(11.3 \%)$ & \\
& Paramedical/nursing & $91(27.8 \%)$ & $234(52.0 \%)$ & \\
& Administrative & $97(29.7 \%)$ & $01(17.8 \%)$ & \\
& Security & $39(11.9 \%)$ & $84(18.7 \%)$ & \\
& Sanitation & $65(19.9 \%)$ & & \\
\hline
\end{tabular}

Chi-squared test ${ }^{*}$ indicates significant $p$ value. 
Table 2 Comparison of lifestyle characteristics

\begin{tabular}{|c|c|c|c|c|}
\hline Characteristic & & Male $(n=327)$ & Female $(n=450)$ & $p$ value \\
\hline Physical activity & $\begin{array}{l}\text { Low } \\
\text { Moderate } \\
\text { Vigorous }\end{array}$ & $\begin{array}{l}62(19.0 \%) \\
228(69.7 \%) \\
37(11.3 \%)\end{array}$ & $\begin{array}{l}91(20.2 \%) \\
297(66.0 \%) \\
62(13.8 \%)\end{array}$ & 0.486 \\
\hline Strict exercise & $\begin{array}{l}\text { Yes } \\
\text { No }\end{array}$ & $\begin{array}{l}142(43.4 \%) \\
185(56.6 \%)\end{array}$ & $\begin{array}{l}146(32.4 \%) \\
304(67.6 \%)\end{array}$ & $0.002^{*}$ \\
\hline Meditation practice & $\begin{array}{l}\text { Yes } \\
\text { No }\end{array}$ & $\begin{array}{l}107(32.7 \%) \\
220(67.3 \%)\end{array}$ & $\begin{array}{l}135(30.0 \%) \\
315(70.0 \%)\end{array}$ & 0.433 \\
\hline Yoga & $\begin{array}{l}\text { Yes } \\
\text { No }\end{array}$ & $\begin{array}{l}61(18.7 \%) \\
266(81.3 \%)\end{array}$ & $\begin{array}{l}66 \text { (14.7\%) } \\
384 \text { (85.3\%) }\end{array}$ & 0.141 \\
\hline Diet & $\begin{array}{l}\text { Vegetarian } \\
\text { Nonvegetarian }\end{array}$ & $\begin{array}{l}69(21.1 \%) \\
258(78.9 \%)\end{array}$ & $\begin{array}{l}101(22.4 \%) \\
349(77.6 \%)\end{array}$ & 0.662 \\
\hline Abnormal food intake & $\begin{array}{l}\text { Yes } \\
\text { No }\end{array}$ & $\begin{array}{l}112(34.2 \%) \\
215(65.8 \%)\end{array}$ & $\begin{array}{l}127(28.2 \%) \\
323(71.8 \%)\end{array}$ & 0.083 \\
\hline Avoiding bad food & $\begin{array}{l}\text { Yes } \\
\text { No }\end{array}$ & $\begin{array}{l}257(78.6 \%) \\
70(21.4 \%)\end{array}$ & $\begin{array}{l}375(83.3 \%) \\
75(16.7 \%)\end{array}$ & 0.113 \\
\hline Diabetes & $\begin{array}{l}\text { Yes } \\
\text { No }\end{array}$ & $\begin{array}{l}32(9.8 \%) \\
295(90.2 \%)\end{array}$ & $\begin{array}{l}25(5.6 \%) \\
425(94.4 \%)\end{array}$ & $0.036^{*}$ \\
\hline Hypertension & $\begin{array}{l}\text { Yes } \\
\text { No }\end{array}$ & $\begin{array}{l}47(14.4 \%) \\
280(85.6 \%)\end{array}$ & $\begin{array}{l}28(6.2 \%) \\
422(93.8 \%)\end{array}$ & $<0.0001^{*}$ \\
\hline
\end{tabular}

Fischer's exact test. ${ }^{*}$ indicates significant $p$ value.

Table 3 Comparison of well-being characteristics

\begin{tabular}{|c|c|c|c|c|}
\hline Characteristic & & Male $(n=327)$ & Female $(n=450)$ & $p$-val \\
\hline Physical health & $\begin{array}{l}\text { Serious health risks } \\
\text { Some well-being risks } \\
\text { Good } \\
\text { Outstanding }\end{array}$ & $\begin{array}{l}38(11.6 \%) \\
116(35.5 \%) \\
114(34.9 \%) \\
59(18.0 \%)\end{array}$ & $\begin{array}{l}70(15.5 \%) \\
219(48.7 \%) \\
112(24.9 \%) \\
49(10.9 \%)\end{array}$ & $<0.0001^{*}$ \\
\hline Mental health & $\begin{array}{l}\text { Serious health risks } \\
\text { Some well-being risks } \\
\text { Good } \\
\text { Outstanding }\end{array}$ & $\begin{array}{l}29(8.9 \%) \\
100(30.6 \%) \\
107(32.7 \%) \\
91(27.8 \%)\end{array}$ & $\begin{array}{l}38(8.4 \%) \\
166(37.0 \%) \\
163(36.2 \%) \\
83(18.4 \%)\end{array}$ & $0.016^{*}$ \\
\hline Social health & $\begin{array}{l}\text { Serious health risks } \\
\text { Some well-being risks } \\
\text { Good } \\
\text { Outstanding }\end{array}$ & $\begin{array}{l}21(6.4 \%) \\
42(12.8 \%) \\
101(31.0 \%) \\
163(49.8 \%)\end{array}$ & $\begin{array}{l}27(6.0 \%) \\
68(15.1 \%) \\
197(43.8 \%) \\
158(35.1 \%)\end{array}$ & $<0.0001^{*}$ \\
\hline Spiritual health & $\begin{array}{l}\text { Serious health risks } \\
\text { Some well-being risks } \\
\text { Good } \\
\text { Outstanding }\end{array}$ & $\begin{array}{l}30(9.2 \%) \\
44(13.4 \%) \\
131(40.1 \%) \\
122(37.3 \%)\end{array}$ & $\begin{array}{l}36(8.0 \%) \\
89(19.8 \%) \\
187(41.5 \%) \\
138(30.7 \%)\end{array}$ & 0.062 \\
\hline Intellectual health & $\begin{array}{l}\text { Serious health risks } \\
\text { Some well-being risks } \\
\text { Good } \\
\text { Outstanding }\end{array}$ & $\begin{array}{l}20(6.1 \%) \\
52(15.9 \%) \\
97(29.7 \%) \\
158(48.3 \%)\end{array}$ & $\begin{array}{l}31(6.9 \%) \\
68(15.1 \%) \\
185(41.1 \%) \\
166(36.9 \%)\end{array}$ & $0.005^{*}$ \\
\hline Overall well-being score & $\begin{array}{l}\text { Serious health risks } \\
\text { Some well-being risks } \\
\text { Good } \\
\text { Outstanding }\end{array}$ & $\begin{array}{l}16(4.9 \%) \\
86(26.3 \%) \\
125(38.2 \%) \\
100(30.6 \%)\end{array}$ & $\begin{array}{l}21(4.7 \%) \\
159(35.3 \%) \\
192(42.7 \%) \\
78(17.3 \%)\end{array}$ & $<0.0001^{*}$ \\
\hline
\end{tabular}

Chi-squared test ${ }^{*}$ indicates significant $p$ value.

was observed in terms of spiritual health. Physical health and overall well-being were good in male employees than in females. The mental health risk is higher in female employees. Outstanding intellectual health was observed more in male employees than in female employees. Study participants included doctors, nurses, paramedical staff, administrative staff, security staff, sanitary, and general workers.
The overall well-being showed no risk in $68.8 \%$ of male and $60 \%$ of female employees, indicating that majority of the healthcare employees were conscious of the benefits of leading a healthy lifestyle. The little difference between male and female employees might be because of their tight schedule with the family/household responsibilities, which may limit the female employees to improve their physical 
and social health indicators. The higher percentage of risk associated with female employees regarding their physical well-being was due to poor exercise practices and abnormal food intake behavior. This is because of the lack of time and engagement with family, factors which female healthcare employees have to take into account. ${ }^{15}$ Most of the staff members showed negligible well-being risks regarding their mental, social, spiritual, and intellectual health as they were educated, nonsmokers, nonalcoholics, nonhypertensive, nondiabetic, and practitioners of meditation and yoga.

With these findings, we propose to implement yoga and meditation for all the employees, irrespective of their profession, gender, designation, and organization to improve their health indicators, including physical, mental, social, spiritual and intellectual health. This implementation is more important for female employees as they can educate her children, husbands, family members and, ultimately, society; thereby, leading to the emergence of a healthy nation.

\section{Limitations}

These finding were extracted from the subgroup analysis of the main study conducted by the authors. This is a single center study.

\section{Conclusions}

The overall well-being of healthcare staff was good at our tertiary care hospital, and the outstanding/good well-being rate was higher in male employees than in female employees. Female employees experienced risk to their physical health; hence, we propose to implement yoga and meditation for all the employees, irrespective of their profession, gender, and designation to improve their health indicators.

\section{Author Contributions:}

VV: Protocol designing, manuscript review, and approval; VK: Data analysis, manuscript review, and approval; KL: Protocol designing, initial manuscript writing, analysis, and approval; AK: Manuscript review and approval; MRP: Manuscript review and approval.

\section{Audio}

Audio file for this article is available at https://doi. org/10.1055/s-0041-1723912.

\section{Source of Funding}

None.

\section{Conflicts of Interest}

None declared.

\section{Acknowledgments}

We thank Dr. M. Krishna Santoshi for providing the translations of the well-being assessment questionnaires prepared for this study.

\section{References}

1 World Health Organization. Constitution of the World Health Organization - Basic Documents, Forty-fifth edition, Supplement, October 2006. Available at https://www. who.int/governance/eb/who_constitution_en.pdf. Accessed June 19, 2020

2 Gambera PJ, Schneeman BO, Davis PA. Use of the Food Guide Pyramid and US Dietary Guidelines to improve dietary intake and reduce cardiovascular risk in active-duty Air Force members. J Am Diet Assoc 1995;95(11):1268-1273

3 American Heart Association. Physical Activity Improves Quality of Life. Available at: http://www.heart.org/ HEARTORG/GettingHealthy/PhysicalActivity/FitnessBasics/ Physical-activity-improves-quality-of-life_UCM_307977_ Article.jsp. Accessed February 18, 2020

4 Huppert FA. Psychological well-being: Evidence regarding its causes and consequences. Appl Psychol Health Well-Being 2009;1:137-164

5 National Health Policy. Ministry of Health and Family Welfare, Govt. Of India. Available at: https://www.nhp. gov.in/nhpfiles/national_health_policy_2017.pdf Accessed September 13, 2019

6 World Health Organization. Global Atlas on Cardiovascular Disease Prevention and Control. Available at: https://www. who.int/cardiovascular_diseases/publications/atlas_cvd/en/. Accessed April 13, 2019

7 Mcdonald S, Thompson C, Women's Health. Elsevier; Australia:; 2005 90-121

8 McEwen M, Pullis B, Community-Based Nursing: An Introduction. 3rd ed. Elsevier: Saunders; 2008

9 Kaplan L, Education and Mental Health. Harper and Row: New York; 1971

10 Mahdipour N, Shahnazi H, Hassanzadeh A, Sharifirad G.. The effect of educational intervention on health promoting lifestyle: focusing on middle-aged women. J Educ Health Promot 2015;4-51

11 Aghamolaei T, Tavafian SS, Hassani L. Exercise self-efficacy, exercise perceived benefits and barriers among students in Hormozgan University of Medical Sciences. Majallah-i Ipidimiyuluzhi-i Iran 2009;4:9-15

12 Giacobbi PR Jr, Stancil M, Hardin B, Bryant L. Physical activity and quality of life experienced by highly active individuals with physical disabilities. Adapt Phys Activ Q 2008;25(3):189-207

13 Kaplan RM, Sieber WJ, Ganiata TG. The quality of wellbeing-scale: comparison of the interviewer-administered version with a self-administered questionnaire. Psychol Health 1997; 12:783-791

14 Velam V, Kasala L, Durgaprasad R, Bitla AR. Assessment of healthy lifestyle and wellbeing status among the employees of a tertiary care hospital. J NTR Univ Health Sci 2020;9:20-24

15 Jun SY, Kim J, Choi H, et al. Physical activity of workers in a hospital. Int J Environ Res Public Health 2019;16(4):532 